\title{
Volatile chemical emissions from fragranced baby products
}

\author{
Neda Nematollahi ${ }^{1,2}$ (D) $\cdot$ Augustine Doronila $^{2}$ - Patrick J. Mornane ${ }^{2} \cdot$ Alex Duan $^{2} \cdot$ Spas D. Kolev $^{2}$. \\ Anne Steinemann ${ }^{1,3,4}$
}

Received: 4 May 2018 / Accepted: 8 June 2018 / Published online: 22 June 2018

(C) The Author(s) 2018

\begin{abstract}
Fragranced consumer products have been associated with adverse effects on human health. Babies are exposed to a variety of fragranced consumer products, which can emit numerous volatile organic compounds (VOCs), some considered potentially hazardous. However, fragranced baby products are exempt from disclosure of all ingredients. Consequently, parents and the public have little information on product emissions. This study investigates VOCs emitted from a range of fragranced baby products, including baby hair shampoos, body washes, lotions, creams, ointments, oils, hair sprays, and fragrance. The products were analysed using gas chromatography/mass spectrometry (GC/MS) headspace analysis. Of the 42 baby products tested, 21 products made claims of green, organic, or all-natural. Results of the analysis found 684 VOCs emitted collectively from the 42 products, representing 228 different VOCs. Of these 684 VOCs, 207 are classified as potentially hazardous under federal regulations, representing 43 different VOCs. The most common VOCs emitted were limonene, acetaldehyde, ethanol, alphapinene, linalool, beta-myrcene, acetone, and beta-pinene. A comparison between ingredients emitted and ingredients listed reveals that only $5 \%$ of the 684 VOCs, including $12 \%$ of 207 potentially hazardous VOCs, were listed on the product label, safety data sheet, or website. More than $95 \%$ of both green and regular products emitted one or more potentially hazardous VOCs. Further, emissions of the most prevalent VOCs from green, organic, or all-natural products were not significantly different from regular products. Results from this study can help improve public awareness about emissions from baby products, with the aim to reduce pollutant exposure and potential adverse effects on babies.
\end{abstract}

Keywords Baby products $\cdot$ Fragrance $\cdot$ Volatile organic compounds $\cdot$ Emissions $\cdot$ Ingredients

Electronic supplementary material The online version of this article (https://doi.org/10.1007/s11869-018-0593-1) contains supplementary material, which is available to authorized users.

Neda Nematollahi

nnematollahi@student.unimelb.edu.au

1 Department of Infrastructure Engineering, Melbourne School of Engineering, The University of Melbourne, Melbourne, VIC 3010, Australia

2 School of Chemistry, The University of Melbourne, Melbourne, VIC 3010, Australia

3 College of Science and Engineering, James Cook University, Townsville, QLD 4811, Australia

4 Climate, Atmospheric Sciences, and Physical Oceanography, Scripps Institution of Oceanography, University of California, San Diego, La Jolla, CA 92093, USA

\section{Introduction}

Volatile organic compounds (VOCs) are a major category of pollutants, associated with adverse effects on human health (e.g., World Health Organization (WHO) 2018; National Institutes of Health (NIH) 2018; Safe Work Australia (SWA) 2018; Wallace 2001). Fragranced consumer products, widely used in society, emit numerous VOCs. Previous studies have found more than 150 different VOCs emitted from fragranced products, including terpenes such as limonene and alpha-pinene, and hazardous air pollutants such as formaldehyde and acetaldehyde (Steinemann 2015). Fragranced consumer products (or, for brevity, fragranced products) are defined as products with an added fragrance or scent, such as air fresheners, deodorizers, cleaning products, laundry supplies, household items, perfume, and personal care products (Steinemann 2015), as well as items for babies.

Exposure to fragranced consumer products is widespread. For instance, an estimated $98.5 \%$ of Australians are exposed to fragrance products at least once a week from their own use, 
others' use, or both (Steinemann 2016, 2017). For babies, while comparable population studies are lacking in Australia, some international studies have found average use of baby shampoo, cleaning liquid or gel, and moisturising cream, respectively, as 2.9, 4.4, and $1.4 \mathrm{~g} /$ day (Gomez-Berrada et al. 2017) and 1.55, 2.91, and $2.99 \mathrm{~g} /$ day (Lee et al. 2017).

Exposure to fragranced consumer products has been associated with health problems such as asthma attacks, migraine headaches, respiratory difficulties, and allergic reactions among adults (Steinemann 2016, 2017; Weinberg et al. 2017). In young children, exposure to VOCs from household products, such as air fresheners, has been associated with infant diarrhoea and earache (Farrow et al. 2003). Babies can be exposed to product VOCs through epidermal, inhalation, and ingestion routes (Ott et al. 2007) as well as in utero (Bagasra et al. 2013).

The precise and full ingredients of fragranced products are not required to be fully disclosed (Lunny et al. 2017). The disclosure requirements depend on the type of product. For consumer products such as cleaning supplies, laundry products, air fresheners, and household items, no law in Australia requires disclosure of all ingredients. For personal care products, ingredients need to be listed on product labels, but the general term "fragrance" or "parfum" can be listed instead of the specific fragrance ingredients. However, a single "fragrance" in a product is typically a mixture of several dozen chemicals (Steinemann et al. 2011). Baby products are treated the same as adult products for the purposes of ingredient disclosure. Thus, fragranced baby consumer products (other than personal care products) have no requirement to disclose all ingredients, and baby personal care products are required to disclose ingredients except those in fragrance mixtures (Lunny et al. 2017).

Lack of knowledge of full ingredients may impair consumer choice. Consumers may be attracted to "natural" (or green or organic) products, assuming they may contain fewer chemicals of concern (Klaschka 2016). However, previous studies have discovered that products called natural, green, and organic emitted hazardous air pollutants similar to their regular counterparts (Steinemann 2015). Currently, there is no objective basis for claims of green or natural baby products.
For organic baby products, Australian Certified Organic (ACO) provides a detailed standard (Australian certified Organic (ACO) 2018). Among the specifications, products should consist of at least $95 \%$ organic ingredients to be called "organic." For products less than $95 \%$ organic, labels can make reference to the specific organic ingredients.

Previous research on VOC emissions from fragranced consumer products found the most common compounds were ethanol and limonene (Steinemann 2015), limonene (Dimitroulopoulou et al. 2015), and limonene and linalool (ter Burg et al. 2014). In addition, other terpenes such as alpha-pinene and beta-pinene and other volatiles such as acetone, acetaldehyde, benzyl acetate, and methanol were also common (Steinemann 2015). However, no prior research was identified that specifically analysed the VOCs emitted from fragranced baby products.

This article reports on the first known study to investigate the VOCs emitted from fragranced baby products, including both regular products and green products. In addition, this study compares the ingredients emitted from the products with the ingredients listed on the product label, safety data sheet, and website. Moreover, the emitted chemicals are compared with those classified as potentially hazardous under federal regulations. Finally, emissions between regular and green products are contrasted, as well as their links with hazard classifications and labelling.

\section{Materials and methods}

Headspace GC/MS was used to identify chemicals emitted from 42 baby fragranced products in two categories: 21 regular and 21 green. The regular category includes 9 shampoos (hair shampoos, conditioners, and body washes), 9 lotions (lotions, creams, ointments, and oils), 2 hair sprays, and 1 fragrance spray. The green category includes 12 shampoos (hair shampoos, conditioners, and body washes), 8 lotions (lotions, creams, and oils), and 1 anti-bug spray. All of these 42 products were purchased from stores in Australia, including groceries, pharmacies, and organic food stores.

Table 1 VOCs emitted from 42 baby products compared with VOCs listed

\begin{tabular}{|c|c|c|c|c|c|}
\hline \multirow[t]{2}{*}{ Type } & \multirow[t]{2}{*}{ Number of products } & \multicolumn{2}{|l|}{ Emitted } & \multicolumn{2}{|l|}{ Listed } \\
\hline & & All VOCs & Potentially hazardous VOCs & All VOCs & Potentially hazardous VOCs \\
\hline \multirow[t]{2}{*}{ Regular } & \multirow[t]{2}{*}{21} & 286 occurrences & 95 occurrences & 13 occurrences & 9 occurrences \\
\hline & & 137 identities & 30 identities & 5 identities & 2 identities \\
\hline \multirow[t]{2}{*}{ Green } & \multirow[t]{2}{*}{21} & 398 occurrences & 112 occurrences & 21 occurrences & 16 occurrences \\
\hline & & 154 identities & 33 identities & 4 identities & 3 identities \\
\hline \multirow[t]{2}{*}{ Total } & \multirow[t]{2}{*}{42} & 684 occurrences & 207 occurrences & 34 occurrences & 25 occurrences \\
\hline & & 228 identities & 43 identities & 7 identities & 3 identities \\
\hline
\end{tabular}


Table 2 Most prevalent compounds among baby products

\begin{tabular}{|c|c|c|c|c|}
\hline \multirow[t]{2}{*}{ Compound } & \multirow[t]{2}{*}{ CAS no. } & \multicolumn{3}{|c|}{ Prevalence (no. of products) } \\
\hline & & Total & Regular & Green \\
\hline \multicolumn{5}{|l|}{ All products $(n=42)$} \\
\hline Limonene* & $138-86-3$ & 28 & 11 & 17 \\
\hline Acetaldehyde* & $75-07-0$ & 23 & 10 & 13 \\
\hline Ethanol* & $64-17-5$ & 23 & 14 & 9 \\
\hline alpha-Pinene & $80-56-8$ & 21 & 8 & 13 \\
\hline Linalool & $78-70-6$ & 20 & 4 & 16 \\
\hline beta-Myrcene & $123-35-3$ & 19 & 6 & 13 \\
\hline Acetone* & $67-64-1$ & 17 & 5 & 12 \\
\hline beta-Pinene & $127-91-3$ & 17 & 7 & 10 \\
\hline Eucalyptol & $470-82-6$ & 14 & 4 & 10 \\
\hline Ethyl butyrate & $105-54-4$ & 13 & 8 & 5 \\
\hline 3-Carene & $13,466-78-9$ & 12 & 3 & 9 \\
\hline Phenoxyethanol* & $122-99-6$ & 12 & 8 & 4 \\
\hline Benzyl alcohol* & $100-51-6$ & 11 & 4 & 7 \\
\hline Benzyl acetate & $140-11-4$ & 10 & 5 & 5 \\
\hline Camphene & $79-92-5$ & 10 & 3 & 7 \\
\hline Camphor & $76-22-2$ & 10 & 2 & 8 \\
\hline gamma-Terpinene & $99-85-4$ & 10 & 3 & 7 \\
\hline \multicolumn{5}{|c|}{ Regular products $(n=21)$} \\
\hline Ethanol* & $64-17-5$ & 14 & & \\
\hline Limonene* & $138-86-3$ & 11 & & \\
\hline Acetaldehyde* & $75-07-0$ & 10 & & \\
\hline alpha-Pinene & $80-56-8$ & 8 & & \\
\hline Ethyl butyrate & $105-54-4$ & 8 & & \\
\hline Phenoxyethanol* & $122-99-6$ & 8 & & \\
\hline \multicolumn{5}{|c|}{ Green products $(n=21)$} \\
\hline Limonene* & $138-86-3$ & 17 & & \\
\hline Linalool & $78-70-6$ & 16 & & \\
\hline Acetaldehyde* & $75-07-0$ & 13 & & \\
\hline beta-Myrcene & $123-35-3$ & 13 & & \\
\hline alpha-Pinene & $80-56-8$ & 13 & & \\
\hline Acetone* & $67-64-1$ & 12 & & \\
\hline Eucalyptol & $470-82-6$ & 10 & & \\
\hline beta-Pinene & $127-91-3$ & 10 & & \\
\hline Ethanol* & $64-17-5$ & 9 & & \\
\hline 3-Carene & $13,466-78-9$ & 9 & & \\
\hline Linalool acetate & $115-95-7$ & 8 & & \\
\hline Camphor & $76-22-2$ & 8 & & \\
\hline
\end{tabular}

*Classified as hazardous under Safe Work Australia, Hazardous Chemical Information System (SWA 2018)

"Green" products are defined in this study as the products with the claim of "certified organic," "certified green," "green," "organic," "natural," "no petrochemicals," "non-toxic," "plant-based," and "essential oils" for the whole products or their ingredients on their product label, safety data sheet, or website. "Regular" products are the products not in the green category.

"Baby" products are defined in this study as products containing specific designations, such as wording (e.g., "baby shampoo") or illustrations (e.g., picture of a baby), that they are intended for use on infants and toddlers.

"Fragranced" products are identified in this study as products containing fragrance, parfum, aromatic extracts, or essential oils.

Headspace GC/MS of the baby products was performed using a Shimadzu GC/MS-QP2010 Plus instrument coupled to an automated Shimadzu AOC-5000 sample injection system. Approximately $2 \mathrm{~g}$ of each baby product was weighed into a $10-\mathrm{mL}$ amber vial. Each vial was then tightly sealed with a magnetic screw cap with a PTFE/silicone septum. Samples were incubated at $40{ }^{\circ} \mathrm{C}$ for $1 \mathrm{~h}$ immediately prior to injection of $2.5 \mathrm{~mL}$ of the headspace into the injection port heated at $240{ }^{\circ} \mathrm{C}$ (split ratio 25). Separation was performed on a BPX-VOL capillary column $(30 \mathrm{~m} \times 0.25 \mathrm{~mm}, 1.4 \mu \mathrm{m}$ film thickness) using helium as the carrier gas (flow rate $30 \mathrm{~cm} / \mathrm{s}$ ). The oven temperature was kept at $35^{\circ} \mathrm{C}$ for $3 \mathrm{~min}$, then increased by $5^{\circ} \mathrm{C} / \mathrm{min}$ to $220^{\circ} \mathrm{C}$ and held at this temperature for $5 \mathrm{~min}$. The total run time was $45 \mathrm{~min}$. The mass spectrometer ion source and interface temperatures were maintained at 200 and $240{ }^{\circ} \mathrm{C}$, respectively. The mass spectrometer was operated in full scan mode between $\mathrm{m} / \mathrm{z} 25$ and 400 . Blanks were analysed periodically each day to account for any background impurities. The volatile sample components were identified based on the mass spectral library of the National Institute of Standards and Technology NIST Version 2.0 (Stein 2008).

Two regulatory analyses were performed to identify whether chemicals emitted from baby products could be classified as (i) potentially hazardous under Australian regulations or (ii) potentially carcinogenic under the World Health Organization. For (i), Safe Work Australia (SWA) maintains a Hazardous Chemical Information System (HCIS) that permits identification of chemicals with hazard classifications (Safe Work Australia (SWA) 2018). For (ii), the World Health Organization, International Agency for Research on Cancer (IARC) (World Health Organization (WHO) 2018), evaluates the carcinogenic risk of chemicals to humans. However, these analyses do not imply that the chemicals identified are the only ones with potential hazards. Furthermore, these analyses did not assess whether the products that contained these chemicals could pose any potential hazards as a whole.

\section{Results and discussion}

\section{VOCs emitted}

A summary of all VOCs emitted from "green" and "regular" baby products is provided in Table 1 . The term "VOC 
Table 3 Compounds classified as potentially hazardous* among baby products

\begin{tabular}{|c|c|c|c|c|}
\hline \multirow[t]{2}{*}{ Compound } & \multirow[t]{2}{*}{ CAS no. } & \multicolumn{3}{|c|}{ Prevalence (no. of products) } \\
\hline & & Total & Regular & Green \\
\hline Limonene & $138-86-3$ & 28 & 11 & 17 \\
\hline Acetaldehyde & 75-07-0 & 23 & 10 & 13 \\
\hline Ethanol & $64-17-5$ & 23 & 14 & 9 \\
\hline Acetone & 67-64-1 & 17 & 5 & 12 \\
\hline Phenoxyethanol & $122-99-6$ & 12 & 8 & 4 \\
\hline Benzyl alcohol & $100-51-6$ & 11 & 4 & 7 \\
\hline Isopropyl alcohol & $67-63-0$ & 9 & 4 & 5 \\
\hline Ethyl Acetate & $141-78-6$ & 8 & 5 & 3 \\
\hline 1-Octanol & $111-87-5$ & 7 & 1 & 6 \\
\hline Pentane & $109-66-0$ & 6 & 3 & 3 \\
\hline Isoamyl acetate & $123-92-2$ & 5 & 4 & 1 \\
\hline 2,4-Dimethylhexane & $589-43-5$ & 4 & 0 & 4 \\
\hline Toluene & $108-88-3$ & 4 & 1 & 3 \\
\hline 2-Methylbutyl acetate & $624-41-9$ & 3 & 2 & 1 \\
\hline Cyclohexane & $110-82-7$ & 3 & 1 & 2 \\
\hline Hexane & $110-54-3$ & 3 & 1 & 2 \\
\hline Methanol & $67-56-1$ & 3 & 2 & 1 \\
\hline Octamethylcyclotetrasiloxane & $556-67-2$ & 3 & 3 & 0 \\
\hline Propanal & $123-38-6$ & 3 & 3 & 0 \\
\hline 2-Butenal & $4170-30-3$ & 2 & 1 & 1 \\
\hline 2-Methyl-1-propene & $115-11-7$ & 2 & 0 & 2 \\
\hline 2-Methylpentane & $107-83-5$ & 2 & 0 & 2 \\
\hline 3-Methylhexane & $589-34-4$ & 2 & 1 & 1 \\
\hline Benzaldehyde & $100-52-7$ & 2 & 1 & 1 \\
\hline Butyl acetate & $123-86-4$ & 2 & 1 & 1 \\
\hline Isobutyl 2-methyl-2-propenoate & $97-86-9$ & 2 & 0 & 2 \\
\hline Tetrahydrofuran & $109-99-9$ & 2 & 2 & 0 \\
\hline (2Z)-3,7-dimethylocta-2,6-dienal & $106-26-3$ & 1 & 1 & 0 \\
\hline 1-Hexanol & $111-27-3$ & 1 & 1 & 0 \\
\hline 2,4-Dimethylpentane & $108-08-7$ & 1 & 0 & 1 \\
\hline 2,4-Pentanedione & $123-54-6$ & 1 & 0 & 1 \\
\hline 3-Methylpentane & $96-14-0$ & 1 & 0 & 1 \\
\hline Amyl acetate & $628-63-7$ & 1 & 0 & 1 \\
\hline Benzyl benzoate & $120-51-4$ & 1 & 1 & 0 \\
\hline Butane & $106-97-8$ & 1 & 1 & 0 \\
\hline Citral & $5392-40-5$ & 1 & 0 & 1 \\
\hline Dichloromethane & $75-09-2$ & 1 & 1 & 0 \\
\hline Ethyl lactate & $97-64-3$ & 1 & 0 & 1 \\
\hline Ethyl methyl ether & $540-67-0$ & 1 & 1 & 0 \\
\hline Ethyl propionate & $105-37-3$ & 1 & 1 & 0 \\
\hline Methylcyclohexane & $108-87-2$ & 1 & 0 & 1 \\
\hline Octane & $111-65-9$ & 1 & 0 & 1 \\
\hline Pentyl acetate & $628-63-7$ & 1 & 0 & 1 \\
\hline
\end{tabular}

*Classified as hazardous under Safe Work Australia, Hazardous Chemical Information System (SWA 2018) occurrences" refers to the number of individual VOC peaks detected by GC/MS, where each peak represents an ingredient in the product. The term "VOC identities" refers to the number of different VOCs, where each VOC is present in one or more of the products. Among the 42 products, a total of 684 VOC occurrences representing 228 VOC identities were detected. Each baby product emitted between 1 and 47 VOCs (see Supplementary Tables 1 and 2, available online). Complete data on VOCs identified for all 42 products, green products, and regular products are provided as Supplementary Tables 3, 4, and 5 (available online).

\section{Most prevalent}

Among the 42 products, the most prevalent VOCs (in at least $40 \%$ of the products) were limonene, acetaldehyde, ethanol, alpha-pinene, linalool, beta-myrcene, acetone, and beta-pinene. In regular products, the six most prevalent VOCs were ethanol, limonene, acetaldehyde, alphapinene, ethyl butyrate, and phenoxyethanol. In green products, the six most prevalent VOCs were limonene, linalool, acetaldehyde, beta-myrcene, alpha-pinene, and acetone. Among all the identified VOCs, limonene was 
Table 4 Compounds classified for carcinogenic risk

\begin{tabular}{lcllll}
\hline \multirow{2}{*}{ Compound } & CAS no. & Classification group & \multicolumn{2}{l}{ Prevalence (no. of products) } \\
\cline { 5 - 6 } & & & Total & Regular & Green \\
\hline Acetaldehyde & $75-07-0$ & $2 \mathrm{~B}$ & 23 & 10 & 13 \\
Isopropyl alcohol & $67-63-0$ & 3 & 9 & 4 & 5 \\
Toluene & $108-88-3$ & 3 & 4 & 1 & 3 \\
Tetrahydrofuran & $109-99-9$ & $2 \mathrm{~B}$ & 2 & 2 & 0 \\
2-Butenal & $4170-30-3$ & 3 & 2 & 1 & 1 \\
Dichloromethane & $75-09-2$ & $2 \mathrm{~A}$ & 1 & 1 & 0 \\
\hline
\end{tabular}

Group 2A: Probably carcinogenic to humans, Group 2B: Possibly carcinogenic to humans, Group 3: Not classifiable as to its carcinogenicity to humans (World Health Organization (WHO) 2018) the most common, found in $67 \%$ of the products (see Table 2 for the most prevalent compounds).

\section{Regulatory classifications}

Of the 684 VOC occurrences, 207 are classified as potentially hazardous under Australian regulations (Table 3), and 95\% of products emitted at least one potentially hazardous VOC. Among the most prevalent VOCs (in at least $40 \%$ of the products), $50 \%$ are classified as potentially hazardous: limonene, acetaldehyde, ethanol, and acetone. Also, among these 684 VOC occurrences, 25 are classified as possibly carcinogenic to humans and 1 is classified as probably carcinogenic to humans (Table 4). However, none of these carcinogenic compounds were listed on any product label, safety data sheet, or website.

\section{Green products}

Among the green products, 20 emitted at least 1 VOCs classified as potentially hazardous (Supplementary Table 1, available online). Among the regular products, 20 emitted at least 1 VOCs classified as potentially hazardous (Supplementary Table 2, available online). Among the most prevalent VOCs also classified as potentially hazardous, $75 \%$ are similar among regular and green products. Comparing the 21 regular and 21 green products, no significant difference was found in the most prevalent VOCs $(p<0.05, t$ test).

\section{Listing of ingredients}

Among all the 684 VOC occurrences, only 34 were listed on any baby product label, safety data sheet, or website. Thus, $5 \%$ of all volatile chemicals identified were listed. Further, among all the 207 VOCs classified as potentially hazardous, only 25 were listed on any baby product label, safety data sheet, or website. Thus, $88 \%$ of all potentially hazardous volatile chemicals identified were undisclosed.

\section{Limitations}

This analysis focused on the primary VOC emissions, even though secondary pollutants (such as formaldehyde) could also be generated. Further, the study focused on VOCs, even though other chemical classes (such as semi-volatile or nonvolatile organic compounds) could also pose potential hazards. Finally, the relative safety or hazard of products depends on many factors (e.g., VOC concentrations, frequency, and duration of exposure), and this study focused exclusively on identifying VOC emissions.

\section{Conclusions}

This study provides the results of VOCs emitted from 42 common fragranced baby products, finding a total of 684 VOCs emitted (representing 228 different VOCs), with 207 VOCs emitted (representing 43 different VOCs) classified as potentially hazardous. However, only $5 \%$ of all VOCs and $12 \%$ of potentially hazardous VOCs were listed on any product label, safety data sheet, or website. Moreover, emissions of the most prevalent VOCs from green, organic, and natural fragranced baby products were not significantly different from regular baby products. The results of this study can contribute to improved awareness of product ingredients and to reduce the risk of exposure for babies.

Funding information This study received support from the Australian Government Research Training Program Scholarship (RTP) through the University of Melbourne, the Australian Department of Education and Training (Australian Postgraduate Award), the Commonwealth Scientific and Industrial Research Organization (CSIRO), and the Trace Analysis for Chemical, Earth and Environmental Sciences (TrACEES) platform of The University of Melbourne. This article is dedicated to the memory of Neda Yarmahmoudi.

Open Access This article is distributed under the terms of the Creative Commons Attribution 4.0 International License (http:// creativecommons.org/licenses/by/4.0/), which permits unrestricted use, distribution, and reproduction in any medium, provided you give 
appropriate credit to the original author(s) and the source, provide a link to the Creative Commons license, and indicate if changes were made.

\section{References}

Australian certified Organic (ACO), Australia's largest certifier for organic and biodynamic produce, http://www.aco.net.au/Pages/Operators/ COSMOSStandards.aspx, (accessed June 5, 2018)

Bagasra O, Golkar Z, Garcia M, Rice LN, Pace DG (2013) Role of perfumes in pathogenesis of autism. Med Hypotheses 80:795-803. https://doi.org/10.1016/j.mehy.2013.03.014

Dimitroulopoulou C, Trantallidi M, Carrer P, Efthimiou GC, Bartzis JG (2015) EPHECT II: exposure assessment to household consumer products. Sci Total Environ 536:890-902. https://doi.org/10.1016/ j.scitotenv.2015.05.138

Farrow A, Taylor H, Northstone K, Golding J (2003) Symptoms of mothers and infants related to total volatile organic compounds in household products. Arch Environ Health 58:633-641. https://doi. org/10.3200/AEOH.58.10.633-641

Gomez-Berrada MP, Ficheux AS, Guillou S, Berge C, de Javel D, Roudot AC, Ferret PJ (2017) Consumption and exposure assessment to cosmetic products for children under 2 years old. Food Chem Toxicol 105:151-160. https://doi.org/10.1016/j.fct.2017.04.011

Klaschka U (2016) Are natural compounds used in personal care products toxic for the aquatic environment? Sust Chem Pharm 4:13-20. https://doi.org/10.1016/j.scp.2016.07.002

Lee E, Yun J, Ha J, Park BC, Park GH, Kim HR, Hong SP, Kim KB, Kim MH (2017) Assessment of exposure for baby cosmetic care products in a Korean population. Food Chem Toxicol 106:107-113. https:// doi.org/10.1016/j.fct.2017.05.039

Lunny S, Nelson R, Steinemann A (2017) Something in the air but not on the label: a call for increased regulatory ingredient disclosure for fragranced consumer products. Univ NSWLaw J 40:1366-1391

National Institutes of Health (NIH), US National Library of Medicine, TOXNET, https://toxnet.nlm.nih.gov/ (accessed June 5, 2018)
Ott W, Steinemann A, Wallace L (eds) (2007) Exposure Analysis. CRC Press, Boca Raton SSI

Safe Work Australia (SWA), Hazardous Chemical Information System (HCIS): Search Hazardous Chemicals, http:/hcis.safeworkaustralia. gov.au/HazardousChemical, (accessed June 5, 2018)

Stein SE (2008) NIST Standard Reference Database 1A. In: The National Institute of Standards and Technology NIST. pp 1-49

Steinemann A (2015) Volatile emissions from common consumer products. Air Qual Atmos Health 8:273-281. https://doi.org/10.1007/ s11869-015-0327-6

Steinemann A (2016) Fragranced consumer products: exposures and effects from emissions. Air Qual Atmos Health 9:861-866. https://doi. org/10.1007/s11869-016-0442-z

Steinemann A (2017) Health and societal effects from exposure to fragranced consumer products. Prev Med Rep 5:45-47. https://doi. org/10.1016/j.pmedr.2016.11.011

Steinemann A, MacGregor IC, Gordon SM, Gallager LG, Davis AL, Ribeiro DS, Wallace LA (2011) Fragranced consumer products: chemicals emitted, ingredients unlisted. Environ Impact Assess Rev 31:328-333. https://doi.org/10.1016/j.eiar.2010.08.002

ter Burg W, Bouma K, Schakel DJ, Wijnhoven SWP, van Engelen J, van Loveren H, Ezendam J (2014) Assessment of the risk of respiratory sensitization from fragrance allergens released by air fresheners. Inhal Toxicol 26:310-318. https://doi.org/10.3109/08958378.2014. 888110

Wallace LA (2001) Human exposure to volatile organic pollutants: implications for indoor air studies. Annu Rev Energy Environ 26:269301. https://doi.org/10.1146/annurev.energy.28.050302.105623

Weinberg JL, Flattery J, Harrison R (2017) Fragrances and work-related asthma-California surveillance data, 1993-2012. J Asthma 54: 1041-1050. https://doi.org/10.1080/02770903.2017.1299755

World Health Organization (WHO), International Agency for Research on Cancer (IARC): IARC Monogr Eval Carcinog Risks Hum, list of classifications, volumes 1-120, http://monographs.iarc.fr/ENG/ Classification/latest_classif.php, (accessed June 5, 2018) 